MATEC Web of Conferences 25, 04007 (2015)

DOI: $10.1051 /$ matecconf/ 20152504007

(C) Owned by the authors, published by EDP Sciences, 2015

\title{
A Study on the Fracture Control of Rock Bolts in High Ground Pressure Roadways of Deep Mines
}

\author{
Jinglin Wen \& Fuxing Jiang \\ College of Civil and Environmental Engineering, University Of Science \& Technology Beijing, Beijing, China
}

Jinhai Liu

School of Safety Engineering, North China Institute of Science and Technology, Beijing, China

Yongming Yin

Institute of Mine Safety Technology, China Academy of Safety Science and Technology, Beijing, China

Yichao Zhang

CCTEG Xi'an Research Institute, Xi'an, Shaanxi, China

\begin{abstract}
According to the frequent fractures of rock bolts in high ground pressure roadways of deep mines, this paper analyzes the mechanism of fractures and concludes that high ground pressure and material defects are main reasons for the fracture of rock bolts. The basic idea of fracture control of rock bolts in high ground pressure roadways of deep mines is to increase the yield load and the limit load of rock bolt materials and reduce the actual load of rock bolts. There are four ways of controlling rock bolt fracture: increasing the rock bolt diameter, strengthening bolt materials, weakening support rigidity and the implementation of double supporting. With the roadway support of the 2302 working face of a coal mine as the project background, this paper carries out a study on the effect of two schemes, increasing the rock bolt diameter and the double supporting technique through methods of theoretical analysis, numerical simulation and so on. It determines the most reasonable diameter of rock bolts and the best delay distance of secondary support. Practices indicate that rock bolt fracture can be effectively controlled through the double supporting technique, which strengthens the roof and two sides through the first supporting technique and strengthens side angles through the secondary supporting technique.
\end{abstract}

Keywords: deep mine; high ground pressure roadway; rock bolting; fracture control

\section{INTRODUCTION}

Rock bolting has now become the preferred way of coal mine roadway support in our country ${ }^{[1-5]}$, playing an important role in maintaining roadway stability and mining safety. However, some mines have been in the stage of deep mining of kilometers with the increase of mining depth at an annual rate of $8-10 \mathrm{~m}^{[6-8]}$. Influenced by the complex environment of three "high" and one "disturbance", the control and support of roadway stability becomes more difficult in the stage of deep mining. Failures of supporting structures caused by rock bolt fractures become prominent day by day. In order to solve the problem of rock bolt fracture and failure, Jiping $\mathrm{Du}$, et al. ${ }^{[10]}$ pointed out through mechanical property tests that rock conditions have high requirements on the mechanical property coordination of components in the rock bolting system, such as rock bolt, anchor agent, supporting plate, steel belt and nut. Their mechanical properties should be reasonably coordinated based on the breaking force of rock bolts. Binyin $\mathrm{He}$, et al. ${ }^{[11]}$ investigated and analyzed forms and reasons of fractures of rock bolts and anchor cables in gob-side entries and proposed that mining deployment should be conducted, and extensible rock bolts and anchor cables should be used. Nianjie Ma, et al. ${ }^{[12]}$ analyzed the mechanism of bolt tail fracture caused by the eccentric load and developed a new type of metal bolt with a thick tail to prevent the bolt tail fracture. However, all these researches are carried out on bolt fractures of shallow-buried roadways and fractures of rock bolts in high ground pressure roadways of deep mines are not solved yet. With the roadway support of the 2302 working face of a coal mine as the project background, this paper carries out a study on the fracture control of rock bolts in high ground pressure roadways of deep mines through methods of theoretical analysis, numerical simulation, project practice, and so on, aiming at providing a theoretical basis for the surrounding rock control of rock bolts in high ground pressure roadways of deep mines.

2 MECHANISM OF FRACTURE CONTROL OF ROCK BOLTS IN HIGH GROUND PRESSURE ROADWAYS OF DEEP MINES

There are mainly two reasons for rock bolt fracture. 


\section{MATEC Web of Conferences}

First, the load borne by a rock bolt exceeds the limit load of the whole rock bolt. Second, manufacturing deficiencies and material deficiencies reduce the designed limit load of the rock bolt. The former is an external cause, namely the problem of force source, which is the result of the high ground pressure of deep mines. The latter is an internal cause, namely the technological problem, which is the weakening result of material deficiencies on rock bolt strength.

\subsection{Increase the yield load and the limit load of a rock bolt}

Figure 1 is the characteristic curve of rock bolting The yellow dot in the figure represents the current working condition of a rock bolt and the working condition of the rock bolt is in the position of point a. The black circle stands for the ideal working condition of the rock bolt, which means that the ideal working condition is in the position of $b$. As for the currently-used rock bolt, it is very likely to be broken when the working condition is in the limit state or close to the limit state. The strained condition of the rock bolt will be improved if measures are taken to move the working condition of the rock bolt towards the left. Concrete measures are as follows:

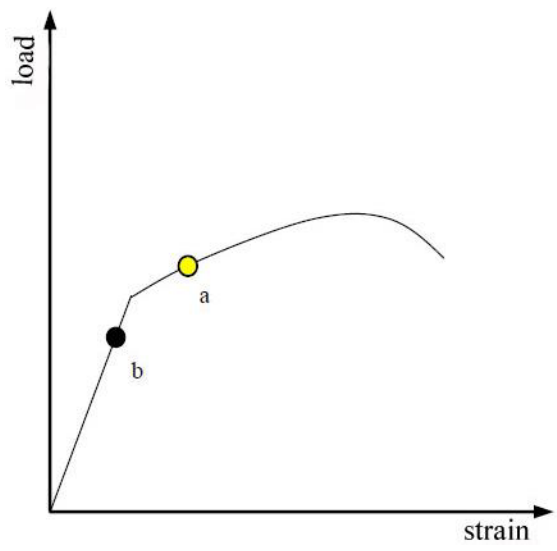

Figure 1. Characteristic curve of rock bolting

(1) Strengthen the rock bolt material. The rock bolt fracture is the result of the competition between the load and the carrying capacity. The fracture might happen when the load is larger than the carrying capacity. The elastic deformation range is enlarged after the rock bolt strength is improved. Compared with normal rock bolts, the working condition is deviated downward and the load is smaller than the carrying capacity. Thus the fracture of the rock bolt can be effectively controlled. For this reason, the rock bolt fracture can be effectively controlled by strengthening rock bolt materials.

(2) Increase rock bolt diameters

The relation among the rock bolt diameter $\mathrm{d}$, the yield load $\mathrm{P}_{\mathrm{s}}$, the breaking load $\mathrm{P}_{\mathrm{e}}$ and the shearing load $\mathrm{P}_{\mathrm{r}}$ is as follows:
$P_{s}=\frac{\sigma_{s} \pi d^{2}}{4}, P_{e}=\frac{\sigma_{e} \pi d^{2}}{4}, P_{\tau}=\frac{\tau \pi d^{2}}{4}$

In this formula, $\sigma_{\mathrm{s}}$ is the yield strength, $\sigma_{\mathrm{e}}$ is the extension strength and $\tau$ is the shearing strength. It can be known from Formula (1) that for the same kind of bolt material, the yield load, the breaking load and the shearing load will be significantly improved after the diameter is increased. If the bolt diameter is increased to $30 \mathrm{~mm}$ from $22 \mathrm{~mm}$, the yield load, the breaking load and the shearing load are increased by $85.9 \%$ correspondingly. Thus the increase of the bolt diameter is able to significantly improve the yield load, the breaking load and the shearing load, which is beneficial to the control of rock bolt fracture.

\subsection{Reduce the actual bearing load of a rock bolt}

After the excavation of a roadway, the load produced by the deformation of the surrounding rock of a roadway is borne by the supporting structure and the surrounding rock jointly. It means that the supporting structure and the surrounding rock form a bearing structure. The supporting structure bears an extremely small load, and the main function of which is to promote the formation of the bearing structure and stop the deformation of the surrounding rock. The interactive relationship of "supporting structure-surrounding rock" is shown in Figure 2:

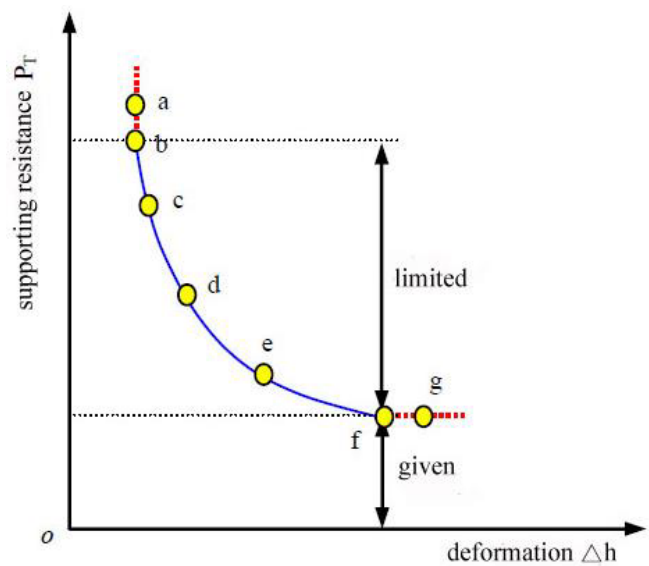

Figure 2. Interactive relation of "supporting structure surrounding rock"

When the supporting condition is located on point a, the deformation of the surrounding rock can be controlled. But the needed supporting resistance is too large. Under normal circumstances, such a large supporting resistance can be hardly achieved by the bolting system. Thus this working condition is illegal. When the supporting condition is located on point $b$, the corresponding supporting resistance of the deformation of the surrounding rock is the limiting stress of the supporting system. Once affected by the stress, the 
rock bolt may be broken. When the supporting condition is located on point $\mathrm{c}$, the deformation of the surrounding rock is effectively controlled. But the needed supporting resistance is relatively large and the working load is much larger than the breaking load of the commonly used rock bolts. This working condition can be achieved by strengthening the strength of the supporting material or by increasing the rock bolt diameter. When the supporting condition is located on point $\mathrm{d}$, the deformation of the surrounding rock is appropriate for the supporting resistance provided by currently-used rock bolts. The rock bolt is in a limiting working condition, which is the state of the supporting system of current deep roadways. Rock bolts can be easily broken in this state. When the supporting condition is located on point $\mathrm{e}$, the deformation of the surrounding rock is large whereas the load borne by the supporting system is small. Thus the rock bolt is in the elastic state and hardly to be broken. When the supporting condition is located on point $f$, the deformation of the surrounding rock is large whereas the load borne by the rock bolt is small. However, such a large deformation might influence the usage of the roadway. When the supporting condition is located on point $g$, the increasing deformation of the surrounding rock is likely to cause roadway instability in spite of the small load borne by the supporting system. This condition is illegal. Therefore, certain deformation of the surrounding rock is permitted so that the actual load of the rock bolt can be effectively reduced. Concrete measures are as follows:

(1) Weaken the rigidity of the supporting system. Being rigid can easily cause the invalidation of rock bolts. After the excavation of a roadway, the surrounding rock stress is adjusted with the company of surrounding rock deformation. In the process of stress adjustment, the surrounding rock deformation might not be released and a large amount of energy is accumulated in the surrounding rock on one hand if the rigidity of the supporting system is too large. On the other hand, a relatively large amount of energy is accumulated in the supporting system under the same deformation condition. The supporting system of an upper state tends to transform to a lower state and the release of energy is very likely to cause rock bolt fracture. The weakening of the rigidity of the supporting system not only improves the toughness of the supporting structure but also plays the role of yielding and reducing the energy accumulation of the supporting system, which is beneficial to the control of rock bolt fracture.

(2) Double supporting. In general cases, the deformation is large and the duration is long before the roadway reaches a stable state. The first supporting is required immediately after the excavation in order to restrict the deformation of the surrounding rock, which allows the surrounding rock to have certain deformation. After a certain degree of surrounding rock deformation and energy releasing, the secondary supporting is conducted to restrain the deformation. The secondary supporting should be carried out before the invalidation of the first supporting when the deformation rate tends to be stable. The main purpose of the secondary supporting is yielding so as to lower the load borne by the rock bolt and control rock bolt fractures.

\section{FRACTURE CONTROL OF ROCK BOLTS IN HIGH GROUND PRESSURE ROADWAYS OF DEEP MINES}

The basic idea of fracture control of rock bolts in high ground pressure roadways of deep mines is to increase the limit load of rock bolt materials and reduce the actual load of rock bolts. Specific measures include increasing bolt diameter, strengthening bolt materials, weakening support rigidity and secondary support. Three principles should be taken into account when measures of controlling rock bolt fracture are selected according to specific conditions: 1 . The principle of considering control. Measures that are taken not only can effectively control the deformation of the roadway surrounding rock but also can control the rock bolt fracture, avoiding changing the control of the roadway surrounding rock deformation for the control of rock bolt fracture. 2 . The principle of easy implementation. Measures that are taken should be able to adapt to the current technological level. Considering the above two principles comprehensively, increasing bolt diameter and the implementation of double supporting are selected. The implementation principle of the two measures is analyzed and specific parameters are optimized below.

\subsection{Implementation principle}

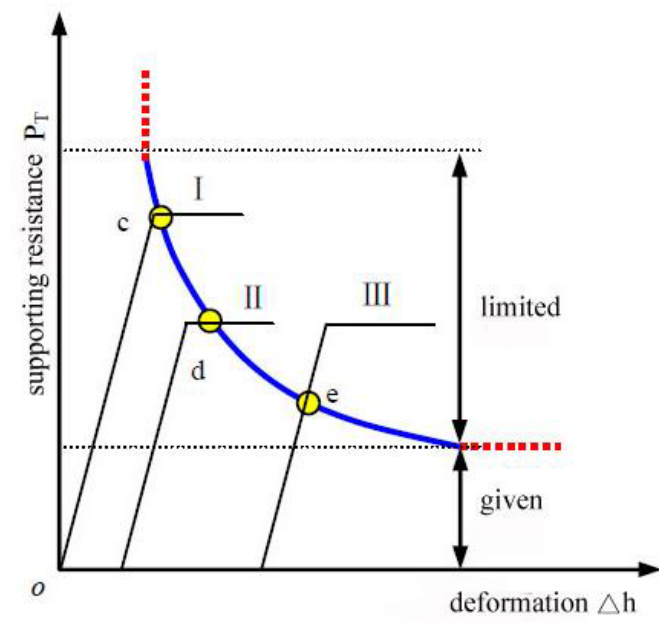

Figure 3. Schematic diagram of rock bolt fracture control

Figure 3 is the schematic diagram of the control measure of rock bolt fracture. In this figure, I is the operating characteristic curve after the increase of the 


\section{MATEC Web of Conferences}

rock bolt diameter, II is the operating characteristic curve of the current rock bolt and III is the operating characteristic curve of the secondary supporting.

It can be seen from Figure 3 that the bearing capacity of the rock bolt increases after the rock bolt diameter is increased. If it is loaded from the original point, the corresponding condition point is $\mathrm{c}$ and the rock bolt is still in a limiting working condition where fractures happen easily. If it is loaded from the corresponding point of II, the working condition point is moved downward to $d$ and the rock bolt is in an elastic state. However, compared with the limit load, the load borne by the rock bolt is still quite small. So the rock bolt fracture can be effectively controlled. When the secondary supporting is implemented, the rock bolt is loaded from the corresponding point of III. The working condition point is e and the point of II is moved downward. The rock bolt is also in an elastic state. Although there is a certain deformation of the surrounding rock bolt, the bearing capacity of the rock bolt is reduced and the rock bolt fracture can be effectively controlled.

\subsection{Parameters optimization}

Specific parameters of the two measures are analyzed and optimized with the numerical simulation software FLAC $^{3 \mathrm{D}}$. The dimension of the established numerical model is $60 \mathrm{~m} \times 60 \mathrm{~m} \times 60 \mathrm{~m}$. The thickness of the simulated coal seam is $8.4 \mathrm{~m}$ and the burial depth is $800 \mathrm{~m}$. The simulated roadway tunnels along the floor. The size of the fracture surface is $4.8 \mathrm{~m} \times 3.6 \mathrm{~m}$. In order to simplify the model, the immediate roof thickness, the basic roof thickness and the overlay stratum thickness are respectively $3 \mathrm{~m}, 4.8 \mathrm{~m}$ and $18 \mathrm{~m}$. Thicknesses of the direct floor, the old floor and the underlay stratum are respectively $3 \mathrm{~m}, 4.8 \mathrm{~m}$ and $18 \mathrm{~m}$. Horizontal displacement constraints are imposed all around the model. Vertical displacement constraints are imposed on the floor. The uniformly distributed load of $20 \mathrm{MPa}$ is imposed on the roof.

\section{(1) Optimization of the rock bolt diameter}

Bolt fracture conditions of the surrounding rock with different bolt diameters are shown in Figure 4. It can be seen from the figure that rock bolts are broken when the diameter is $20 \mathrm{~mm}$ or $22 \mathrm{~mm}$. Rock bolts in the middle of the roof, on the top of two sides and on the base angle are broken when the diameter is $24 \mathrm{~mm}$. Rock bolts on the lower part of the left side is broken when the diameter is $26 \mathrm{~mm}$. Rock bolts are not broken when the diameter is $28 \mathrm{~mm}$ and $30 \mathrm{~mm}$. Thus the number of broken rock bolts in the roadway decreases with the increase of the rock bolt diameter.

In order to determine a reasonable bolt diameter, the relation between the bolt diameter and the vertical stress peak, the surrounding rock displacement, the plastic range and the bolt strained condition is summarized in Figure 5. It can be seen from the figure that the vertical stress peak, the roof subsidence, the two-sided displacement, the plastic range and the bolt strained condition tend to be stable when the rock bolt diameter is larger than $28 \mathrm{~mm}$. Therefore, it is more suitable that $28 \mathrm{~mm}$ is selected as the lower limit of the rock bolt diameter.

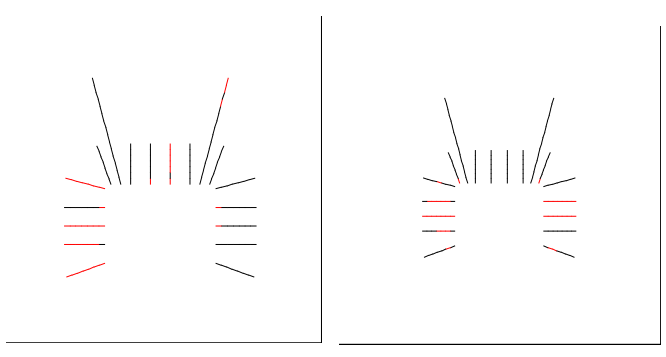

(a) Bolt diameter $20 \mathrm{~mm}$

(b) Bolt diameter $22 \mathrm{~mm}$

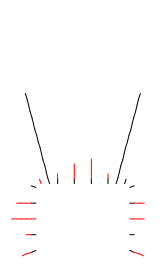

(c) Bolt diameter $24 \mathrm{~mm}$

(d) Bolt diameter $26 \mathrm{~mm}$

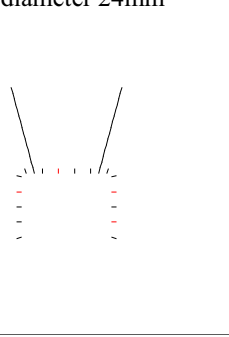

(e) Bolt diameter $28 \mathrm{~mm}$

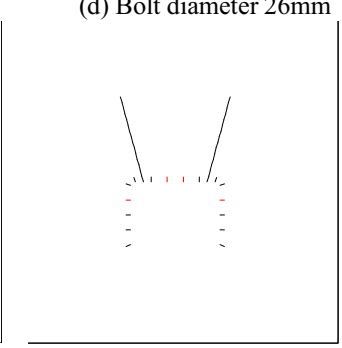

(f) Bolt diameter 30mm
Figure 4. Strained conditions of surrounding rock bolts of different diameters

\section{(2) Implementation of double supporting}

The deformation of the deep coal roadway is large and fast in the preliminary stage. If the first supporting technology with high strength and high pre-stressing force is adopted, the rock bolt might be broken due to the excessive energy accumulated in the surrounding rock. Side angle is the location where the rock bolt fracture mostly happens, the reason of which is that the shearing stress is large. Rock bolt fractures caused by the shearing stress adjustment of side angles can be avoided through the double supporting technique, which strengthens roof and two sides through the first supporting technique and strengthens side angles through the secondary supporting technique. The reasonable delay distance of the secondary supporting is determined with the numerical simulation method. According to the field observation, rock bolt fractures mainly happen at shoulder angles and nests. Simulated 


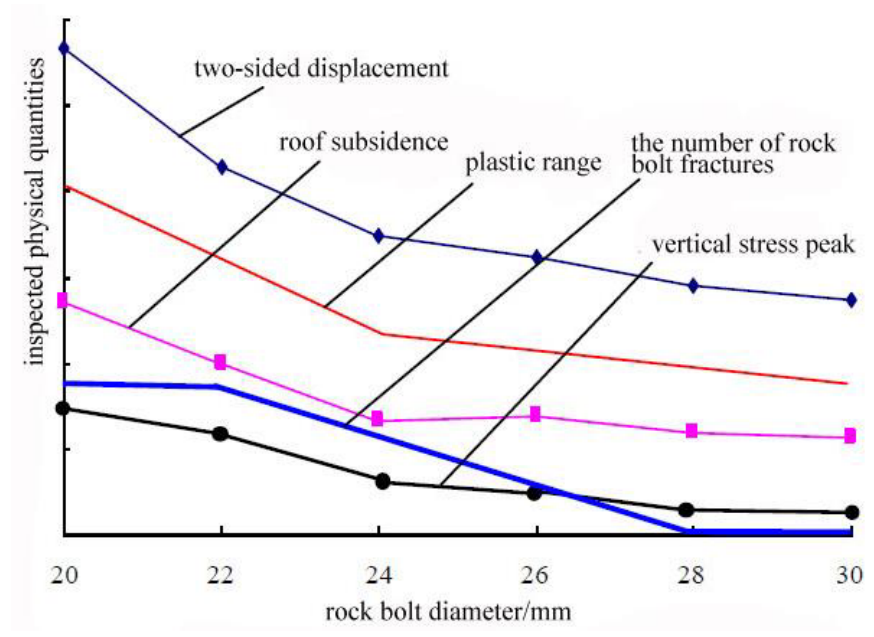

Figure 5. Determination of the rock bolt diameter

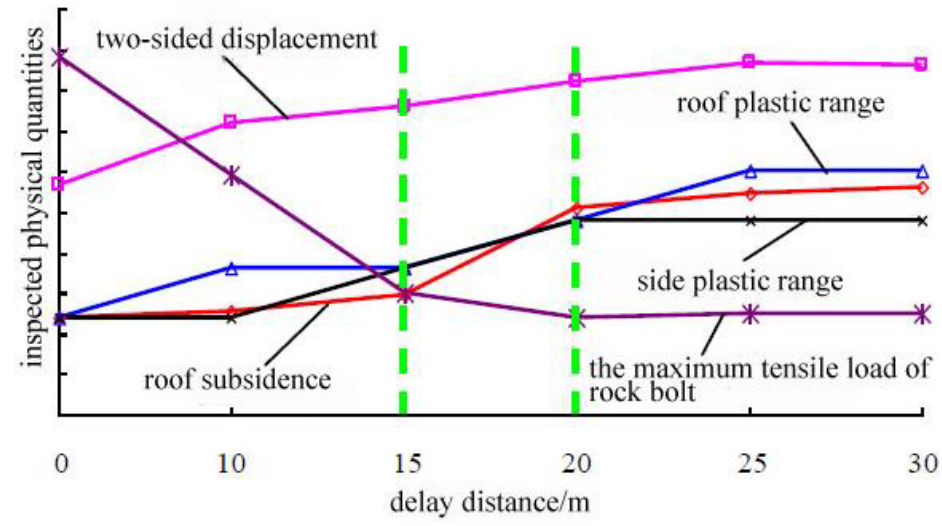

Figure 6. Determination of the delay distance of the secondary supporting

distances of bolt supporting delay and tunneling of the two locations are respectively $5 \mathrm{~m}, 10 \mathrm{~m}, 15 \mathrm{~m}, 20 \mathrm{~m}$, $25 \mathrm{~m}$ and $30 \mathrm{~m}$. Supporting parameters are HRB500 high strength bolt steel of $\Phi 22 \times 2,500 \mathrm{~mm}$ at the top and two sides with an inter-row space of $850 \times 1,000 \mathrm{~mm}$.

In order to determine a reasonable delay distance of the secondary supporting, the relation between the delay distance of the secondary supporting and the surrounding rock displacement, the plastic range, the plastic range and the maximum tensile load of the shoulder rock is summarized in Figure 6. It can be seen from the figure that the roadway roof subsidence and the two-sided displacement increase, the roadway roof plastic range increases, and the side plastic range keeps unchanged with the increase of the delay distance when the delay distance of the secondary supporting is larger than $20 \mathrm{~m}$. The maximum tensile load borne by the shoulder rock tends to be stable and it is smaller than the ultimate tensile load. The roadway roof subsidence, the two-sided displacement, the roadway roof plastic range width and the side plastic range width increase gradually whereas the maximum tensile load of the shoulder rock decreases sharply with the increase of the delay distance when the delay distance of the secondary supporting is smaller than $20 \mathrm{~m}$. Thus it is more suitable that the range of 15 $20 \mathrm{~mm}$ is selected as the delay distance of the secondary supporting.

\section{ENGINEERING APPLICATION}

The lower gangway of the 2302 working face of a coal mine is a solid coal roadway with a sectional dimension of $4.8 \mathrm{~m} \times 3.9 \mathrm{~m}$ and a burial depth of $880 \mathrm{~m}$, which is tunneling along the coal seam floor. The average thickness of the coal seam is $9.0 \mathrm{~m}$ and the Protodyakonov coefficient $\mathrm{f}$ is 1.59 . The immediate roof is siltstone of fracture development with a uni-axial compressive strength of $32.13 \mathrm{MPa}$. The basic roof is hard and fine grain sandstone and the immediate floor 


\section{MATEC Web of Conferences}

is fine siltstone with a uni-axial compressive strength of $95.58 \mathrm{MPa}$. According to the measure results of the ground stress, the major principal stress of the in-situ stress field is a horizontal stress. The maximum horizontal principal stress is $1.67-1.92$ times of the vertical stress. The roadway is a typical high ground stress roadway due to the large burial depth and the high ground stress. The first bolt-mesh-anchor supporting technique is adopted at the outside of the roadway. Rock bolt fractures frequently happen in the process of tunneling, locating on the top and side angles. Fractures of rock bolts at side angles are particularly severe. Although the KMG-500\# high strength rock bolt with the diameter of $22 \mathrm{~mm}$ is adopted, the problem of rock bolt fracture remains unsolved.

In order to solve the problem of rock bolt fracture, the double supporting technique is adopted in the 2302 working face in the process of the lower gangway tunneling, which strengthens roof and two sides through the first supporting and strengthens side angles with delay distances of $15-20 \mathrm{~m}$ through the secondary supporting. Results of the later field investigation indicate that the deformation of the surrounding rock of the roadway is effectively controlled and the number of rock bolt fractures at this location is reduced significantly.

\section{CONCLUSION}

(1) The basic idea of fracture control of rock bolts in high ground pressure roadways of deep mines is to increase the yield load and the limit load of rock bolt materials and reduce the actual load of rock bolts. Corresponding control measures are: increasing the rock bolt diameter, strengthening bolt materials, weakening support rigidity and the implementation of double supporting.

(2) The implementation of double supporting is conductive to the control of local rock bolt fractures. The reasonable delay distance of double supporting is $15-20 \mathrm{~m}$. The problem of rock bolts in high ground pressure roadways of deep mines can be solved fundamentally by increasing the rock bolt diameter, which should not be smaller than $28 \mathrm{~mm}$.

\section{REFERENCES}

[1] Kang Hongpu, Wang Jinhua, \& Lin Jian. 2010. Case studies of rock bolting in coal mine roadways. Chinese Journal of Rock Mechanics and Engineering, 29(4): 649-664.

[2] Hou Chaojiong, Guo Lisheng, \& Gou Panfeng. 1999. Rock Bolting for Coal Roadway. Xuzhou: China University of Mining and Technology Press.

[3] Kang Hongpu. 2005. Study and application of complete rock bolting technology to coal roadway. Chinese Journal of Rock Mechanics and Engineering, 24(21):3959-3 964.

[4] Wang Jinhua. 2007. New development of rock bolting technology for coal roadway in China. Journal of China Coal Society, 32(2): 113-118.

[5] Zhang Nong, \& Gao Mingshi. 2004. High-strength and pretension bolting support of coal roadway and its application. Journal of China University of Mining and Technology, 33(5): 524-527.

[6] Zhou Hongwei, Xie Heping, \& Zuo Jianping. 2005. Developments in researches on mechanical behaviors of rocks under the condition of high ground pressure in depths. Advances in Mechanics, 35(1): 91-99.

[7] Li Shucai, Wang Hanpeng, \& Qian Qihu, et al. 2008. In-situ monitoring research on zonal disintegration of surrounding rock mass in deep mine roadways. Chinese Journal of Rock Mechanics and Engineering, 27(8): 1545-1553.

[8] He Manchao, Xie Heping, \& Peng Suping, et al. 2005. Study on rock mechanics in deep mining engineering. Chinese Journal of Rock Mechanics and Engineering, 24(16): 2803-2813.

[9] Yang Shengbin, He Manchao, \& Liu Wentao, et al. 2008. Mechanics and application research on the floor anchor to control the floor heave of deep soft rock roadway. Chinese Journal of Rock Mechanics and Engineering, 27(S1): 2913-2920.

[10]Du Jiping, \& Hou Chaojiong. 2007. Rational matching on entry bolt supporting components under broken surrounding rock in deep mines. Journal of Mining \&Safety Engineering, 24(4): 401-404.

[11] He Bingying, \& Wang Jue. 2005. Investigation of breakage of bolt and cable in gob side entry. Ground Pressure and Strata Control, 22(1): 55-58.

[12] Ma Nianjie, Liu Shaowei, \& Deng Guangtao, et al. 2005. Roadway bolts tail broken mechanism and design of reasonable structures. Journal of China Coal Society, 30(6):327-331. 